\title{
Neuroimaging Measures as Endophenotypes in Alzheimer's Disease
}

\author{
Meredith N. Braskie, ${ }^{1}$ John M. Ringman, ${ }^{2}$ and Paul M. Thompson' \\ ${ }^{1}$ Laboratory of Neuro Imaging, Department of Neurology, UCLA School of Medicine, 635 Charles Young Drive South, \\ Suite 225, Los Angeles, CA 90095, USA \\ ${ }^{2}$ Mary S. Easton Center for Alzheimer's Disease Research, Department of Neurology, UCLA School of Medicine, \\ 10911 Weyburn Avenue, Suite 200, Los Angeles, CA 90095, USA
}

Correspondence should be addressed to Paul M. Thompson, thompson@loni.ucla.edu

Received 2 September 2010; Revised 8 January 2011; Accepted 7 February 2011

Academic Editor: Lindsay A. Farrer

Copyright (C) 2011 Meredith N. Braskie et al. This is an open access article distributed under the Creative Commons Attribution License, which permits unrestricted use, distribution, and reproduction in any medium, provided the original work is properly cited.

\begin{abstract}
Late onset Alzheimer's disease (AD) is moderately to highly heritable. Apolipoprotein E allele $\varepsilon 4(A P O E 4)$ has been replicated consistently as an $\mathrm{AD}$ risk factor over many studies, and recently confirmed variants in other genes such as CLU, CR1, and PICALM each increase the lifetime risk of $\mathrm{AD}$. However, much of the heritability of $\mathrm{AD}$ remains unexplained. $\mathrm{AD}$ is a complex disease that is diagnosed largely through neuropsychological testing, though neuroimaging measures may be more sensitive for detecting the incipient disease stages. Difficulties in early diagnosis and variable environmental contributions to the disease can obscure genetic relationships in traditional case-control genetic studies. Neuroimaging measures may be used as endophenotypes for AD, offering a reliable, objective tool to search for possible genetic risk factors. Imaging measures might also clarify the specific mechanisms by which proposed risk factors influence the brain.
\end{abstract}

\section{Introduction}

Alzheimer's disease $(\mathrm{AD})$ is thought to be at least $58-74 \%$ heritable [1-3]. However, much of that heritability has yet to be explained by variants in specific risk genes. Mutations in the amyloid precursor protein $(A P P)$ [4], presenilin 1 (PSEN1) [5], and presenilin 2 (PSEN2) $[6,7]$ genes are known to lead to early onset, familial AD. In familial AD, the disease typically follows an autosomal dominant, usually highly penetrant mode of inheritance. However, for many years only the $\varepsilon 4$ allele of apolipoprotein E (APOE4) [8] was identified as a reliable genetic risk factor for late-onset AD. On average, $24 \%$ of control subjects carry at least one copy of APOE4 [9], and each risk allele carries more than threefold odds of developing $\mathrm{AD}$ [9], although these numbers vary across studies; this is a relatively large odds ratio for a highly prevalent risk gene. Recently, large sample genome-wide association (GWA) studies have successfully identified and replicated associations between several single nucleotide polymorphisms (SNPs) and AD [10] (Table 1), namely, in the CLU [11, 12], PICALM [11-13], and CR1 [13] genes and near the BIN1 and EXOC3L2 genes [12]. Numerous other genetic polymorphisms also have been associated with a diagnosis of $\mathrm{AD}$, but with less statistical evidence, and replication results are frequently inconsistent [14] (http://www.alzgene.org/). Much work yet remains in discovering the sources of $\mathrm{AD}$ heritability. As we note below, large-scale neuroimaging studies provide an approach to discover, replicate, and study new genetic risk factors.

$\mathrm{AD}$ is a complex disease whose onset and trajectory are influenced by (1) environmental factors and (2) many genetic polymorphisms having small effects and/or rare polymorphisms having larger effects. Because contributing genes have large effects in aggregate but small effects individually, association studies typically require large samples to reliably identify the individual contribution of any one polymorphism, especially since stringent corrections for multiple comparisons are required by GWA studies. Additionally, genes involved in either neurodevelopment or degeneration or both may contribute to $\mathrm{AD}$ risk. The onset of $\mathrm{AD}$ is 
TABLe 1: Top AD risk genes.

\begin{tabular}{lllcc}
\hline & Gene & Protein & Population & Polymorphism \\
\hline 1 & APOE_e2/3/4 & apolipoprotein E & all & APOE_e2/3/4* \\
2 & CLU & clusterin & all & rs11136000* \\
3 & EXOC3L2 & exocyst complex component 3-like 2 & all & rs597668 \\
4 & BIN1 & bridging integrator 1 & all & rs744373 \\
5 & PICALM & phosphatidylinositol binding clathrin assembly protein & all & rs541458* \\
6 & SORL1 & sortilin-related receptor & Asian & rs2282649* \\
7 & GWA_14q32.13 & unknown & all & rs11622883 \\
8 & TNK1 & tyrosine kinase non-receptor, 1 & all & rs1554948 \\
9 & ACE & angiotensin I converting enzyme (peptidyl-dipeptidase A) 1 & Caucasian & rs1800764 \\
10 & IL8 & interleukin 8 & all & rs4073 \\
11 & LDLR & low density lipoprotein receptor & all & rs5930 \\
12 & CST3 & cystatin C & Caucasian & rs1064039* \\
13 & CR1 & complement component (3b/4b) receptor 1 (Knops blood group) & all & rs6656401 \\
14 & hCG2039140 & unknown & all & rs1903908 \\
15 & CHRNB2 & cholinergic receptor, nicotinic, beta polypeptide 2 (neuronal) & all & rs4845378 \\
16 & SORCS1 & sortilin-related VPS10 domain containing receptor 1 & all & rs600879 \\
17 & TNF & tumor necrosis factor alpha & Asian & rs4647198 \\
18 & CCR2 & chemokine (C-C motif) receptor 2 & Caucasian & rs1799864 \\
\hline
\end{tabular}

Genes listed represent those most highly associated with AD per alzgene.org [9] as of August 22, 2010. Only those with high or moderate epidemiological evidence are included above. Grading was based on HuGENet (Human Genome Epidemiology Network) interim criteria for the assessment of cumulative evidence of genetic associations [132].

*At least one neuroimaging study has investigated the effects of this polymorphism in the brain.

clinically detectable only when the pathological hallmarks of the disease such as amyloid plaques, neurofibrillary tangles, and neuronal loss have advanced to the point where memory impairment and other behavioral changes become evident. Therefore, symptoms may be manifest when abundant pathology overwhelms an otherwise healthy brain, or limited pathology occurs in a brain whose health and resilience is compromised by cortical thinning, reduced white matter integrity, or restricted blood flow.

It is difficult for case-control studies to identify genetic risk factors for $\mathrm{AD}$ based on clinical diagnosis alone. This is because $\mathrm{AD}$ diagnosis relies on evidence of cognitive deficits identified using standard cognitive tests. Performance on cognitive tests may be influenced by factors unrelated to disease, such as fatigue, anxiety, general test-taking ability, and practice effects. As such, well-educated people suffering from cognitive decline can appear normal in a clinical setting, while cognitively normal worriers may appear to be impaired. Other late-life dementias also may be clinically misdiagnosed as AD. Using brain endophenotypes that are objective and highly reproducible over time may make it easier to identify AD genetic risk factors and to understand their impact on the brain.

In recent multisite efforts, researchers have performed brain scans on and genotyped large numbers of cognitively intact and impaired older adults. These studies have improved the ability of researchers to identify AD-related genes. In this article, we review the results of neuroimaging studies that evaluate the effects on the brain of top
AD-related candidate genes other than $A P O E$ as well as genetic contributions to brain vulnerability. We discuss the findings from GWA studies that have used neuroimaging measures as endophenotypes for $\mathrm{AD}$, and we offer suggestions for future studies. Finally, we discuss multigene and more advanced genetic models as means to identify specific genetic contributions to $\mathrm{AD}$. The main findings of the studies discussed here are summarized in Table 2 by imaging phenotype.

\section{Candidate Gene Approach}

There are two main ways to investigate effects of AD-relevant genes using brain imaging - the first is to study candidate genes already associated with $\mathrm{AD}$, and the second is to use genome-wide scanning to perform an unbiased search of up to a million genetic polymorphisms. Both types of approach have been applied in neuroimaging studies of $\mathrm{AD}$. The earliest studies have focused on the most widely studied candidate gene, $A P O E$.

Although not without conflicting results, many studies have linked APOE4 to neuroimaging measures such as regional hypometabolism assessed using fluorodeoxyglucose positron emission tomography (FDG-PET) (which measures brain glucose metabolism) [15-17], functional magnetic resonance imaging (fMRI) activity (which measures variations in regional levels of blood oxygenation and is thought to reflect both blood flow and neuronal activity) during memory tasks and at rest [18-26], regional brain volume 
TABLE 2: SNPs with AD-relevant effects detected by neuroimaging measures.

\begin{tabular}{|c|c|c|c|c|}
\hline Neuroimaging measure & SNP & Gene & Location $^{c}$ & Neuroimaging association \\
\hline \multirow[t]{10}{*}{ Hippocampal volume or gray matter density } & rs429358/rs7412 (ع2/3/4) $)^{\mathrm{b}}$ & $A P O E$ & $19 q 13.32$ & CG [47], GWA [104] \\
\hline & rs10501927 & CNTN5 & $11 q 22.1$ & CG [47] \\
\hline & rs3851179 & PICALM & $11 \mathrm{q} 14.2$ & CG [47] \\
\hline & rs4646994 & $A C E$ & $17 q 23.3$ & CG $[68]$ \\
\hline & rs $2075650^{b}$ & TOMM40 & $19 \mathrm{q} 13.32$ & GWA [104] \\
\hline & rs4692256 & LOC391642 & $4 \mathrm{p} 15.1$ & GWA [104] \\
\hline & rs10074258 & EFNA5 & $5 q 21.3$ & GWA [108] \\
\hline & rs $12654281^{\mathrm{b}}$ & EFNA5 & $5 \mathrm{q} 21.3$ & GWA [108] \\
\hline & rs10781380 & PRUNE2 & $9 \mathrm{q} 21.2$ & GWA [108] \\
\hline & rs1888414 & FDPSP & $21 \mathrm{q} 21.1$ & GWA [108] \\
\hline \multirow[t]{5}{*}{ ERC thickness } & rs429358/rs7412 ( $\varepsilon 2 / 3 / 4)^{\mathrm{b}}$ & $A P O E$ & $19 q 13.32$ & CG [47] \\
\hline & rs3851179b & PICALM & $11 \mathrm{q} 14.2$ & CG [47] \\
\hline & rs10501927 & CNTN5 & $11 \mathrm{q} 22.1$ & CG [47] \\
\hline & rs $1408077^{\mathrm{b}}$ & CR1 & $1 \mathrm{q} 32.2$ & CG [47] \\
\hline & rs7561528 & BIN1 & $2 \mathrm{q} 14.3$ & CG [47] \\
\hline \multirow[t]{2}{*}{ PHG cortical thickness } & rs429358/rs7412 (ع2/3/4)b & $A P O E$ & $19 q 13.32$ & CG [47] \\
\hline & rs10501927 & CNTN5 & $11 q 22.1$ & CG [47] \\
\hline \multirow[t]{3}{*}{ Amygdala volume } & rs429358/rs7412 $(\varepsilon 2 / 3 / 4)^{\mathrm{b}}$ & $A P O E$ & $19 q 13.32$ & CG [47], GWA [104] \\
\hline & rs $2075650^{\mathrm{b}}$ & TOMM40 & $19 q 13.32$ & GWA [104] \\
\hline & rs4646994 b & $A C E$ & $17 q 23.3$ & CG [68] \\
\hline MTL volume & rs $4935775^{b}$ & SORL1 & $11 \mathrm{q} 24.1$ & CG $[58]$ \\
\hline \multirow[t]{3}{*}{ Temporal pole cortical thickness } & rs429358/rs7412 ( $(\varepsilon 2 / 3 / 4)^{\mathrm{b}}$ & $A P O E$ & $19 q 13.32$ & CG [47] \\
\hline & rs10501927 & CNTN5 & $11 \mathrm{q} 22.1$ & CG [47] \\
\hline & rs7561528 & BIN1 & $2 \mathrm{q} 14.3$ & CG [47] \\
\hline \multirow[t]{3}{*}{ Temporal lobe volume } & rs429368/rs7412 ( $(\varepsilon 2 / 3 / 4)^{\mathrm{b}}$ & $A P O E$ & $19 q 13.32$ & GWA [81] \\
\hline & rs 10845840 & GRIN2B & $12 \mathrm{p} 13.1$ & GWA [81] \\
\hline & rs 2456930 & $\begin{array}{l}\text { chromosome } \\
15 \text { intergenic } \\
\text { region }\end{array}$ & $15 q 22.2$ & GWA [81] \\
\hline Frontal lobe volume & rs3751812 & FTO & $16 q 12.2$ & CG[76] \\
\hline GM density-precuneus & rs10932886 & EPHA4 & $2 \mathrm{q} 36.1$ & GWA [104] \\
\hline \multirow[t]{2}{*}{ GM density-frontal cortex } & rs10932886 & EPHA4 & $2 \mathrm{q} 36.1$ & GWA [104] \\
\hline & rs6463843 & NXPH1 & $7 \mathrm{p} 21.3$ & GWA [104] \\
\hline Regional brain tissue volume in temporal lobe & rs2429582 & CADPS2 & $7 \mathrm{q} 31.32$ & vGWA [113] \\
\hline Regional brain tissue volume in parietal lobe & rs476463 & CSMD2 & $1 \mathrm{p} 35.1$ & vGWA [113] \\
\hline Whole brain volume & rs $1468063^{\mathrm{b}}$ & FAS & $10 q 23.31$ & CG [71] \\
\hline Ventricular volume & rs $1468063^{b}$ & FAS & $10 \mathrm{q} 23.31$ & CG $[71]$ \\
\hline
\end{tabular}


TABle 2: Continued.

\begin{tabular}{|c|c|c|c|c|}
\hline Neuroimaging measure & SNP & Gene & Location $^{c}$ & Neuroimaging association \\
\hline \multirow[t]{7}{*}{ WM lesion volume $\mathrm{e}^{\mathrm{a}}$} & rs10501927 & CNTN5 & $11 \mathrm{q} 22.1$ & CG [47] \\
\hline & rs560573 b & SORL1 & $11 \mathrm{q} 24.1$ & CG [58] \\
\hline & rs $668387^{b}$ & SORL1 & $11 \mathrm{q} 24.1$ & CG [58] \\
\hline & rs689021 $1^{b}$ & SORL1 & $11 \mathrm{q} 24.1$ & CG [58] \\
\hline & rs $641120^{\mathrm{b}}$ & SORL1 & $11 \mathrm{q} 24.1$ & CG [58] \\
\hline & rs $2276346^{b}$ & SORL1 & $11 \mathrm{q} 24.1$ & CG [58] \\
\hline & rs4646994 & $A C E$ & $17 q 23$ & CG [65] \\
\hline WM integrity ${ }^{\mathrm{a}}$ & rs11136000 & $C L U$ & $8 \mathrm{p} 21.1$ & CG [54] \\
\hline
\end{tabular}

This table summarizes the most promising single SNPs relevant to AD research and identified from associations with neuroimaging characteristics. These characteristics show correlations with the SNP alleles either specifically in AD-related regions (in healthy adults) or anywhere in the brain (in normal adults and those with $\mathrm{AD}$ and/or MCI).

Key: GM: gray matter; WM: white matter; MTL: medial temporal lobe; PHG: parahippocampal gyrus; ERC: entorhinal cortex; CG: candidate gene approach; GWA: genome-wide association scan approach; vGWA: voxelwise genome-wide association scan approach.

${ }^{a}$ White matter lesion volume is calculated from a structural MRI scan (usually a T2-weighted scan), while white matter integrity is measured using diffusion tensor imaging and reflects water diffusion directionality.

${ }^{b}$ Previously identified as an AD risk allele [9].

${ }^{c}$ Locations were determined using http://genome.ucsc.edu/ [133], using values from dbSNP build 131.

or cortical thickness (measures of structural gray matter integrity) [27-31], white matter integrity [32-35], cerebral blood flow [36-39], and AD-related pathology such as amyloid and neurofibrillary tangle load [40-44]. Results from such $A P O E$ neuroimaging studies have been reviewed previously [14, 45, 46].

Neuroimaging differences associated with the APOE genotype may result from incipient $\mathrm{AD}$, or they may relate instead to differences specific to the genotype independent of $\mathrm{AD}$ pathology (e.g., developmental differences). If other $\mathrm{AD}$ risk genes were to resemble $A P O E$ in their effects on the brain, it would support the notion that those brain differences are related to the pathological processes of AD. Additionally, determining the effects on the brain of other $\mathrm{AD}$ risk gene variants would help to characterize the mechanisms of those risk alleles, enabling more targeted therapeutic treatments to be developed. Thus far, relatively few neuroimaging studies have examined the effect of $A D$ candidate risk genes other than APOE on the brain (Table 1).

The most recent and comprehensive candidate gene study to date was performed by Biffi and colleagues (2010), who evaluated the effects of top AD risk polymorphisms on six measures shown to predict AD risk and measure disease progression [47]. The authors measured hippocampus, amygdala, and white matter lesion volumes and thickness of the entorhinal cortex, parahippocampal gyrus, and temporal pole cortex in $\mathrm{AD}$ patients, mild cognitively impaired (MCI) patients, and normal controls. People with MCI have some degree of demonstrable cognitive impairment not severe enough to warrant a diagnosis of dementia.
Approximately 10-15\% of those with amnestic MCI convert to probable $\mathrm{AD}$ each year compared with an estimated 1$2 \%$ of similarly aged cognitively intact individuals [48]. MCI therefore can be used as an indicator of early AD-related changes in the brain. The authors focused on confirmed risk polymorphisms and other potential risk variants identified in recent GWA studies. Among these were APOE, CLU, PICALM, CR1, CNTN5, and BIN1. APOE, which encodes apolipoprotein $\mathrm{E}$-an apolipoprotein that interacts with $\beta$ amyloid [49] — was correlated with all brain measures except for white matter lesion volumes. CNTN5, which codes for contactin 5-a protein that may play a role in regional axonal development [50] - is not currently listed as a top $\mathrm{AD}$ risk gene [9]. However, it was associated with all measures except for amygdala volume. All the genetic variants except for $C L U$ were statistically correlated with entorhinal cortex thickness. The CLU gene encodes clusterin (also known as apolipoprotein J)-another apolipoprotein that interacts with $\beta$-amyloid [51]. Additionally, a variant in the PICALM gene, which codes for phosphatidylinositol binding clathrin assembly protein - a protein involved in regulating the fusion of synaptic vesicles [52] — was correlated with hippocampal volume. Finally, BIN1, which encodes bridging integrator $1-$ a protein involved in neurite growth [53]was correlated with temporal pole cortical thickness [47]. The authors suggested that although sample sizes affect the power to detect gene effects, the specificity of relationships with particular polymorphisms may reflect the function and expression patterns of the resulting proteins, possibly elucidating mechanisms that contribute to AD risk [47]. 
The CLU risk variant rs11136000 was not associated with any of the measures here, but our research group recently found that in young healthy adults, the risk allele of that SNP was associated with reduced integrity of broad white matter regions, observed with diffusion tensor imaging [54]. The lipid transport and membrane recycling performed by the clusterin protein [55] may be important to myelin development but not to medial temporal lobe gray matter. Choosing measures that reflect the purported protein function associated with risk genes in question might help to focus the search for gene effects in the brain.

Another $\mathrm{AD}$ gene with structural effects on the brain is SORL1, which encodes the sortilin-related receptor. The gene product is a low-density lipoprotein receptor that may be involved in processing the amyloid precursor protein [56]. SORL1 may also play a role in cardiovascular health [57]. Cuenco and colleagues (2008) evaluated how 30 different polymorphisms in the SORL1 gene related to general cerebral atrophy, hippocampal atrophy, white matter hyperintensities and cerebrovascular disease, which they measured semiquantitatively [58]. Among the variants tested in AfricanAmerican and white AD-control sibships was rs2282649a top $\mathrm{AD}$ genetic risk factor [9]. In whites, this variant was associated with cerebral and hippocampal atrophy as part of a 3 SNP haplotype [58]. SNPs within SORL1 also were associated with white matter hyperintensities in two studies $[58,59]$. The strongest relationship between $\mathrm{rs} 2282649$ and $\mathrm{AD}$ is in Asian populations (as determined in a large metaanalysis) [9]. Future comparisons of SNP effects on the brain in Asians versus Caucasians may clarify how this polymorphism relates to $\mathrm{AD}$.

Babiloni and colleagues (2006) used electroencephalography (EEG) to examine how another $\mathrm{AD}$ risk gene, CST3, affects resting cortical rhythmicity (the frequency of repetitive spiking of neuronal activity) in subjects with $\mathrm{AD}$ and MCI. One haplotype evaluated contained an AD top risk SNP (rs1064039) [60]. CST3 codes for cystatin C, a protein that colocalizes with $\beta$-amyloid [61] and may be involved in the proliferation of neural stem cells [62]. The amplitude decrease of alpha 1 sources (parietal, occipital, and temporal areas) was more pronounced in $\mathrm{AD}$ and $\mathrm{MCI}$ patients with the CST3 risk haplotype, possibly indicating greater amyloid load or neuronal death [60]. Follow-up studies of this polymorphism that evaluate brain atrophy using MRI or amyloid load using PET imaging may be valuable.

Some additional neuroimaging studies of major AD risk genes examined the $A C E$ gene, which codes for angiotensin converting enzyme-a protein that modulates the cardiovascular system by helping to regulate extracellular volume. $A C E$ also affects the central nervous system by influencing neurons in the hippocampus and amygdala and helping to maintain the blood brain barrier [63, 64]. All these studies evaluated the commonly evaluated $A C E$ insertion/deletion (I/D). The ACE D/D polymorphism was associated with increased severity of white matter hyperintensities or cerebral infarction in some $[65,66]$ but not all $[67,68]$ studies. One study found that the I/I genotype was associated with increased $\mathrm{AD}$ risk, and smaller hippocampi and amygdalae [68]. Another found that D carriers with MCI showed differences in resting state fMRI brain activity compared with I homozygotes [63]. The I/D variant examined in these studies is not one of the two currently listed by a large metaanalysis (http://www.alzgene.org/) [9] as being significantly associated with Alzheimer's disease overall, although some evidence links it with $\mathrm{AD}$ risk or unspecified cognitive decline $[69,70]$. Regardless, since this variant in the $A C E$ gene appears to modulate brain structure and function, it would be valuable to investigate the effects of other $A C E$ polymorphisms having stronger relationships to AD: namely rs1800764 and rs4291 [9].

Recently, Erten-Lyons and colleagues (2010) evaluated the effects of a less studied $\mathrm{AD}$ risk gene, FAS, on the brain in 242 older adults who were cognitively intact or had MCI or $\mathrm{AD}$ [71]. FAS codes for the Fas (TNF receptor superfamily, member 6) protein, which may be involved in apoptosis in $\mathrm{AD}$ [72]. The authors evaluated $97 \mathrm{SNPs}$ in or near the FAS gene that had been previously associated with AD. After adjustment for multiple testing, they found that rs 1468063 was associated with faster $\mathrm{AD}$ progression. Carriers of the $\mathrm{T}$ allele of that SNP had greater ventricular volumes and smaller brain volumes in a subgroup of 56 subjects [71].

The candidate gene approach also may be used to evaluate the effects of genes predisposing subjects to characteristics (such as hypertension, obesity, high cholesterol, and diabetes) that increase the risk of AD [73-75] without necessarily being directly involved in the development of classic $\mathrm{AD}$ pathology such as amyloid plaques or neurofibrillary tangles. Examining the effects of these variants in healthy adults and focusing on brain areas susceptible to earliest $\mathrm{AD}$ processes may be productive in isolating polymorphisms that create a vulnerability that $\mathrm{AD}$-related pathology later exploits. Recent work has already demonstrated that some such genes have an effect in the brain. For instance, Ho et al. (2010) recently demonstrated in 206 cognitively intact older adults from the ADNI study that risk allele carriers for rs3751812 in the fat mass and obesity associated gene (FTO) had smaller average brain volumes in frontal and occipital lobes relative to noncarriers (Figure 1) [76]. Those of European descent carrying two copies of the common adverse variant of FTO have increased risk for obesity, relative to those carrying no copies [77]. The connection between FTO and brain atrophy is important, as it suggests one mechanism whereby cardiovascular risk factors (including risk genes) may make the brain more vulnerable to the later effects of AD. The FTO gene may cause brain atrophy by promoting a craving for greater caloric intake resulting in higher body mass index (which is also associated with brain atrophy; $[78,79]$ ). It is also possible that FTO affects the brain by direct gene action to promote tissue atrophy or insufficiency. Even so, a variety of lifestyle factors, including education, diet, and exercise, are associated with reduced brain atrophy. This underscores the value of controlling preventable risk factors for brain atrophy [80].

Other studies have focused on variants associated with genes important for blood pressure regulation and cholesterol levels such as the previously mentioned ACE $[65,66]$ and SORL1 variant studies $[58,59]$. Studies focusing on regions affected early in $\mathrm{AD}$ such as the hippocampus, 


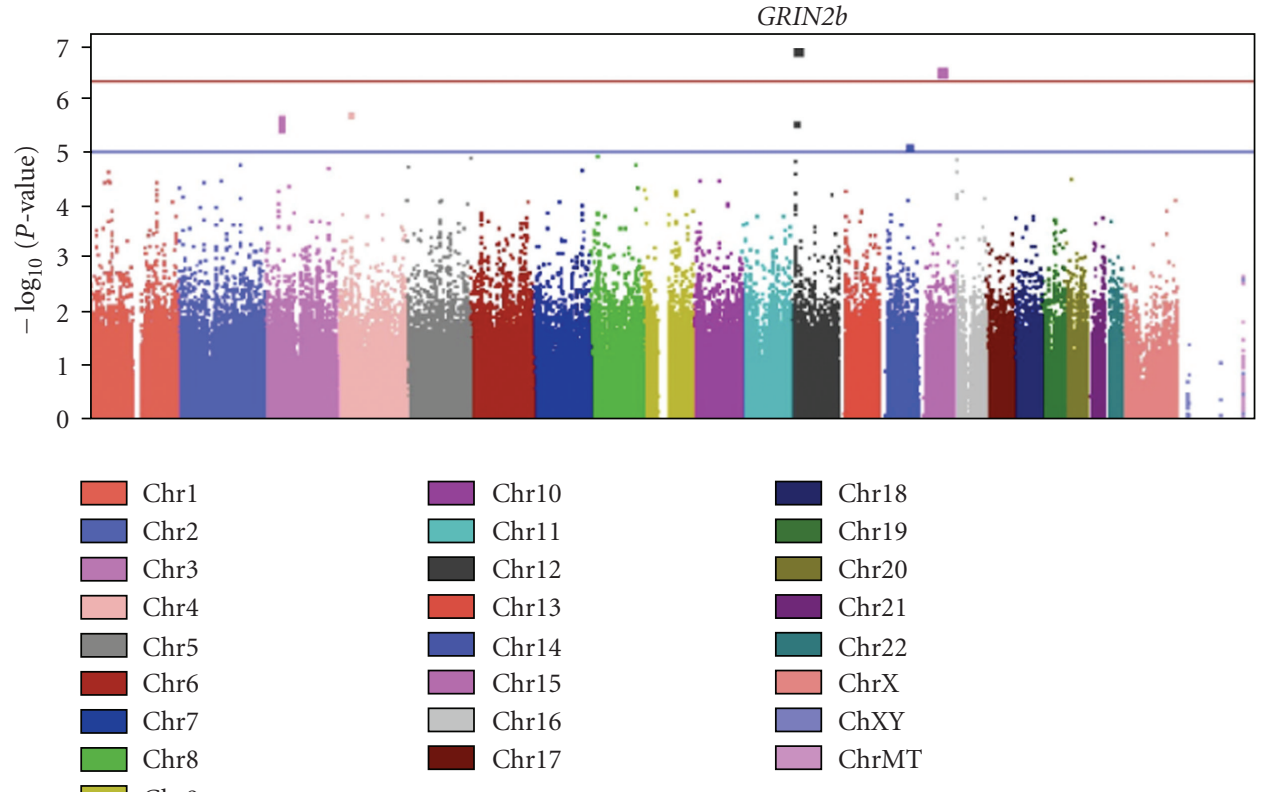

(a)

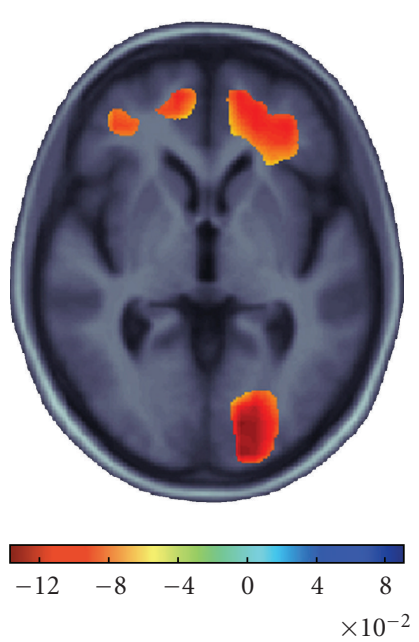

$\Delta$ brain volume associated with FTO risk allele $\left(\mathrm{mm}^{3}\right)$

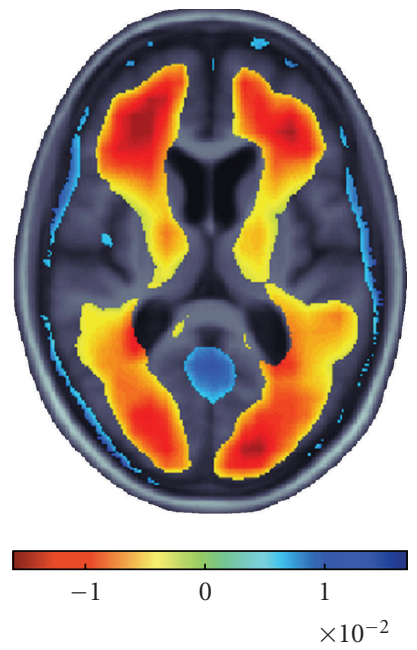

$\Delta$ brain volume associated with increased body mass index $\left(\mathrm{mm}^{3} / \mathrm{kg} \mathrm{m}^{-2}\right)$

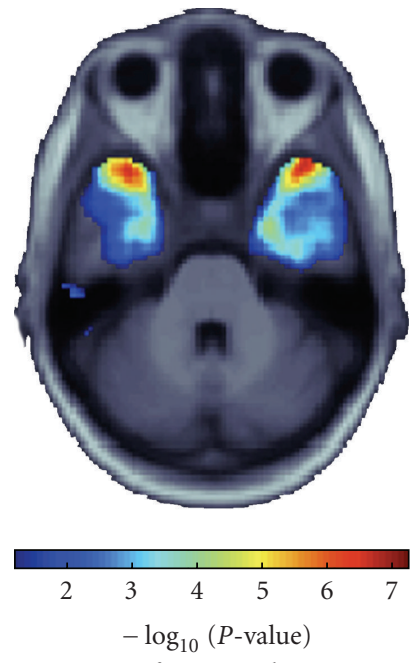

for GRIN2b

effect on temporal

lobe volume

(b)

FIGURE 1: Common genetic variants (single nucleotide polymorphisms) associated with temporal lobe volume in a GWA study are shown in (a) along with an image showing the effects of the top hit, GRIN2b, on brain volume [81].The figure is adapted from Stein et al. (2010) with kind permission from the authors and publishers. (b) shows the effect (regression coefficients) of the candidate obesity gene, FTO, on brain atrophy in a cognitively normal adults and those with MCI and AD [76]. The figure is adapted from Ho et al. (2010) with kind permission from the authors and publishers.

entorhinal cortex [82], and posterior cingulate cortex [15] may be helpful in further elucidating the links between AD and cardiovascular health.

\section{Genome-Wide Association Studies}

Recently, a small number of studies have used genomewide association (GWA) to search for novel genetic variants associated with $\mathrm{AD}$ endophenotypes. Discovering new risk genes would be extremely beneficial to the study of $\mathrm{AD}$. Clinical trials could then selectively enroll, or perform subanalyses on risk allele carriers, who are more likely to decline than noncarriers. Those at heightened genetic risk might also benefit the most from early treatment. Additionally, using $\mathrm{AD}$ risk genes as covariates would boost power in AD-related studies since modeling the identified genetic risk 
factors reduces otherwise unexplained variance in the disease trajectory, making other influential factors easier to detect.

Several initiatives, such as Alzheimer's Disease Neuroimaging Initiative (ADNI) (www.loni.ucla.edu/ADNI), are now searching for new gene risk variants using neuroimaging traits that are highly heritable, easily measured in a reliable way, and associated with $\mathrm{AD}$ [83]. This may be a valuable way to overcome some of the obstacles inherent in diagnosisbased searches for risk polymorphisms. For instance, one might use as an endophenotype the baseline regional neuroimaging measures known to predict longitudinal cognitive decline in amnestic MCI or early AD. Such measures make specific diagnoses unnecessary because they focus on symptoms, namely the confluence of longitudinally decreased cognitive ability with specific functional or structural brain deficits that predict that decrease. Also, as continuous measures that vary across the continuum of normalcy from MCI to $\mathrm{AD}$, neuroimaging measures may offer greater statistical power for genetic analysis than binary diagnostic categories. Suggested criteria for endophenotypes are that the measures are associated with illness, are heritable, are apparent in an individual regardless of whether the illness is active, and that they co-segregate with illness within families [84]. Some neuroimaging measures, such as hippocampal and ventricular volume largely meet these criteria as endophenotypes for $\mathrm{AD}$. Both increased ventricular volume [85-88] and decreased volume of medial temporal lobe structures, especially the hippocampus [87-92] predict cognitive decline, are moderately to highly heritable [93-95], and are associated with $\mathrm{AD}$ and genetic risk for $\mathrm{AD}$ (Table 2). Other measures that show promise in predicting cognitive decline are brain amyloid burden as measured using Pittsburgh Compound B [96] and white matter integrity (in general and perhaps more specifically in the parietal lobe) as measured with diffusion tensor imaging [97] both of which are also highly heritable [98, 99]. Some neuroimaging measures may not yet be considered endophenotypes. For instance, glucose metabolism as measured with FDG-PET [100-102], and cerebral perfusion as measured with arterial spin labeling [103] also may predict cognitive decline, but large-scale heritability studies of these measures in healthy older adults are needed to ascertain their potential for identifying genetic influences. These guidelines may be useful when evaluating the utility of a measure as an endophenotype.

One recent GWA study by Shen and associates (2010) evaluated genetic associations with brain structure using a large number of nonspecific phenotypes. They studied $733 \mathrm{AD}$ and MCI patients and normal controls from the ADNI cohort and controlled for age, sex, education, handedness, and baseline intracranial volume [104]. The authors examined 142 regions of interest and found that the wellknown variants in $A P O E$ (rs429358/rs7412 a.k.a. $\varepsilon 2 / 3 / 4$ ) and in a more newly identified gene, TOMM40 (rs2075650), were strongly associated with bilateral hippocampus and amygdala volumes. Four additional SNPs were associated at the $P<10^{-7}$ level with regional gray matter density. In the EPHA4 gene, rs10932886 was correlated with gray matter density in the left precuneus and bilateral frontal regionsregions in which atrophy occurs in late $\mathrm{AD}$ [105]. EPHA4 codes for the EPH receptor A4-a receptor tyrosine kinase that regulates dendritic spine morphology in pyramidal cells of the adult hippocampus. EPHA4 also helps to control glial glutamate transport resulting in regulation of hippocampal function [106]. Its association with hippocampal structure and function makes this gene an intriguing target for future study. Likewise, rs6463843 in the NXPH1 gene was associated with gray matter density in the left middle orbital frontal gyrus. NXPH1 encodes the neurexophilin 1 protein, which is a physical ligand for $\alpha$-neurexins-proteins that may participate in synaptic function [107]. Finally, rs4692256 (LOC391642) was associated with gray matter density in the right hippocampus, but the function of the genetic material containing that SNP is unknown. The authors also reported a number of other associations at the more liberal $P<10^{-6}$ level [104].

Two other recent ADNI-based GWA studies focused their searches on temporal lobe structures; temporal lobe volume is highly heritable and is also a relatively good predictor of developing AD. Potkin et al. (2009) used a genomewide search for polymorphisms affecting hippocampal gray matter density, and identified novel AD susceptibility genes in 381 subjects who had AD or were normal controls [108]. $\mathrm{AD}$ cases differed in genotype from controls at rs429358 (one of the two SNPs comprising the APOE 2/3/4 genotype), and at rs2075650 in the TOMM40 gene. Using a significance threshold of $P<10^{-7}$ and covarying for age, sex, and the number of APOE4 alleles, four SNPs were associated with right or left hippocampal gray matter density [108]. Two of these, rs10074258 and rs12654281, were in or near the EFNA5 gene [108], which encodes the ephrin-A5 protein implicated in nervous system development including in the hippocampus [109]. The gene function and association with hippocampal structure across multiple SNPs makes it an alluring target for future study. Two other SNPs associated with hippocampal gray matter density at the $P<10^{-7}$ level were rs10781380 in the PRUNE2 gene and rs1888414 near the FDPSP gene [108]. These two SNPs have a less clear tie to AD-related symptoms compared with those in EFNA5. At the $P<10^{-6}$ level, the authors also identified correlations of right or left hippocampal gray matter density with genotypes at an additional 11 SNPs.

In a larger study also using the ADNI dataset, Stein and colleagues (2010) used MRI and GWA to identify SNPs associated with temporal lobe and hippocampal volumes in $742 \mathrm{AD}$ and MCI patients and healthy elderly adults, controlling for age and sex (Figure 1) [81]. The authors also evaluated the relationship between temporal lobe volume and the $A P O E 2 / 3 / 4$ genotype, which was not part of the Illumina gene chip used in the GWA. As expected, APOE4 was associated with lower temporal lobe volume. Additionally, at a significance level of $P<5 \times 10^{-7}$, the authors identified two SNPs that were associated with bilateral temporal lobe volume across diagnoses: rs 10845840 in the GRIN2B gene (independent of an APOE4 effect), and rs2456930, located in an intergenic region of chromosome 15 [81]. The GRIN2B gene codes for a regulatory subunit 2B (NR2B) of the NMDA (N-methyl D-aspartate) glutamate receptor. $\mathrm{NR} 2 \mathrm{~B}$ is implicated in learning, memory, and 
structural plasticity, and cognitive deficits in Alzheimer's disease $[110,111]$. The same glutamate receptor is also the target of memantine [112], a drug designed to slow the progression of $\mathrm{AD}$. This makes GRIN2B an attractive target for future $\mathrm{AD}$ investigations generally, and also specifically with respect to how it may modulate memantine drug effects.

Finally, in the first voxelwise GWA (vGWA) study, Stein and colleagues (2010) examined the effects of genetic variation on brain structure as determined using tensorbased morphometry, while controlling for age and sex [113]. Rather than testing for genetic associations with one or a small number of structural measures, associations were tested at each of hundreds of thousands of voxels in the image-leading to a whole-brain, whole-genome search. The authors evaluated 740 subjects from the ADNI study who had $\mathrm{AD}$ or $\mathrm{MCI}$, or were normal controls, and identified only the most significant SNP association at each voxel. Top SNPs identified within known genes in this GWA search were rs476463 in the CSMD2 gene and rs2429582 in the CADPS2 gene [113]. CSMD2 (CUB and Sushi multiple domains 2) maps to a chromosomal region that may contain a suppressor of oligodendrogliomas [114], although little is yet known about the protein function. CADPS2 codes for $\mathrm{Ca}^{++}$-dependent secretion activator 2 , a protein that regulates synaptic vesicle and large dense core vesicle priming in neurons, and promotes monoamine uptake and storage in neurons [115]. Although no SNP survived a false discovery rate correction at $P<.05$ [113], this method remains promising when larger sample sizes become available. Stringent corrections are needed when searching an entire image for genomic effects, but the size of the search space can be greatly reduced by carrying forward promising voxels to later analyses. Because of this, the sample sizes needed to replicate a GWA finding, when searching an entire image, are typically much smaller than the discovery sample size (as low as 300400 rather than 700 subjects [113]) as the voxels with no effects can be discarded in the replication analyses.

The sample size needed to detect statistical relationships between genetic risk factors and specific brain measures depends upon the measure being studied. Beckett and colleagues (2010) recently compared the ability of various MRI- and PET-derived attributes to track the progression of $\mathrm{MCI}$ and $\mathrm{AD}$ [116]. Regions of interest derived from specific brain voxels showing significant relationships to cognitive impairment in previous studies gave greater power to detect a slowing of the disease than measures related to whole structures such as the hippocampus. The increased power of statistical voxel selection was later reinforced by studies using both MRI [117] and FDG-PET [118]. Such statistically predefined regions of interest may be promising targets of genetic studies in which gene effects can be mapped using statistical mapping approaches. By focusing on regions with greatest statistical effects, the power to detect or replicate genetic effects in follow-up studies is vastly increased [119]. In that regard, imaging studies can avoid a general problem in large-scale genetics; by focusing on promising voxels, replication samples may in fact be smaller than the discovery samples, if the effects of the genes in the brain are somewhat localized. The selection of sets of voxels showing significant genetic associations is helpful to boost power, above and beyond focusing solely on regions that are clinically important to the disease of interest (which is also important). Such an approach has been advocated by Chen et al. (2010) and $\mathrm{Wu}$ et al. (2010) $[118,120]$. There are at least three advantages in focusing on specific voxels over predefined anatomical regions of interest. First, although a given gene variant may affect a region that shows dramatic effects in a given disease, that whole region may not be equally affected. Using a voxelwise approach may help to identify subregions that would provide a more concentrated focus for future replication efforts. An example is a recent study of the brain derived neurotrophic factor $(B D N F)$ genes, in which common variants were associated with brain fiber integrity on DTI, in 455 subjects [119]. When the sample was split into two, the same regions of the white matter showed associations in each subsample, but there would have been no a priori reason to select those regions as implicated. Limiting a search to significant voxels in follow-up studies boosts power by avoiding image wide corrections for statistical tests at voxels less likely to show an effect. Secondly, although the focus of a study may be $\mathrm{AD}$, pathways altered by a specific gene variant may be relevant to multiple complex diseases and disorders. Data collection and analysis are costly in genetic neuroimaging studies. Therefore, reporting all significant results can provide information that may not otherwise be easily obtained but may be useful to researchers at large. Thirdly, image based tests for replication, such as conjunction tests, can be devised that allow specific sets of brain regions, not just specific genes, to be replicated as showing associations (see, e.g., Ho et al. 2010 [76]).

In GWA studies, it is conventional to enforce a significance cut-off of $P<10^{-7}$ or $10^{-8}$. This represents a Bonferroni-type correction for the false positives that could occur when 500,000 SNPs are searched for statistical effects. As adjacent SNPs are somewhat correlated (due to linkage disequilibrium effects), the effective number of tests is slightly fewer than the number of SNPs tested, but even SNPs falling below $P<10^{-7}$ are considered to show "genome-wide evidence" requiring replication in subsequent studies or in meta-analyses of multiple independent datasets. So far, there is no universal agreement as to what statistical threshold for GWA studies is the best. The above ROI-based GWA studies reviewed here all used a threshold of at least $10^{-7}$ to report their top findings [81, 104, 108], which controls for multiple comparisons in the tests performed. Dudbridge and Gusnanto (2008) suggested that a genome-wide significance threshold should not account only for markers that have been tested in a study, but also for all possible genomic variation. This leads to a more conservative threshold of $P<7.2 \times 10^{-8}$ [121]. Because of the required time and cost of collecting and analyzing neuroimaging data, the sample sizes here, although large for imaging studies, remain small for genetic studies. These smaller sample sizes may produce false positives unless independent replication is performed. Still, functionally promising SNPs have been identified in these studies, highlighting numerous replication targets for future work.

All four of the above GWA studies were performed using scans from the ADNI dataset with a high degree 
of overlap of subjects. Even so, the top SNPs were not replicated across studies. This may be due to a number of methodological factors. First, the sample sizes needed to detect a genetic association depend on the minor allele frequency and effect size, and are typically between a few hundred and several thousand subjects. With this limitation, measures that show association in one study may be missing in another. Even different software used to measure the same structure do not give perfectly correlated measures. Also, many associations will be missed due to imprecision in the measures-single gene effects are typically only detectable for measures with the highest precision and reproducibility. Additionally, across studies, the initial genetic searches did not adjust for the same covariates in addition to age and sex. For instance, Potkin and colleagues covaried for APOE genotype [108], but Shen and colleagues covaried for education, handedness, and baseline intracranial volume [104], and the Stein et al. studies did not use additional covariates $[81,113]$. Finally, the choices of ROI and methods of delineating those regions varied across studies. The ENIGMA (Enhancing Neuro Imaging Genetics through Meta-Analysis) project (http://enigma.loni.ucla.edu/) [122] is one of several multicenter initiatives to standardize genetic and imaging methods. Its goal is to empower future replication efforts and make it easier to perform meta-analyses. Because different SNP sets are genotyped in different studies, imputation methods are employed to allow the same set of genomic variations to be queried across every dataset.

Using GWA to evaluate how genetic variance affects $\mathrm{AD}$ endophenotypes in cognitively intact younger and older adults may also aid in identifying $\mathrm{AD}$ genetic risk factors. Genetic variants associated with brain measures in young cognitively normal adults are less likely to be associated with molecular pathology. More likely, they support early vulnerabilities in the brain that $\mathrm{AD}$ pathology later exploits. The polymorphisms may, for instance, relate to health factors that increase the risk of $\mathrm{AD}$, such as obesity and diabetes, or may relate to neural development in regions affected in early $\mathrm{AD}$, such as the hippocampus and entorhinal cortex. Variants identified in cognitively intact older adults may relate to both $\mathrm{AD}$ molecular processes and vulnerabilities in the brain. Using amyloid imaging measures in these subjects may be helpful in identifying genetic risk factors for earliest AD changes.

An imaging measure may be associated with a particular polymorphism during development but may also be related to other gene polymorphisms with respect to degeneration later in life. Therefore, it is not the measurement, but rather its context and other demographic factors that determine whether gene effects relate to neurodevelopment or degeneration. This should be borne in mind when replicating gene effects across cohorts. For instance, in Stein et al. (2011), caudate volume was associated with commonly carried variants in dopamine-related genes, and the effects were found in an large elderly cohort scanned in North America, and replicated in a young adult cohort scanned in Australia [123]. Such replications of SNPs may indicate gene effects that persist throughout life. The use of two very different samples is likely to identify genes of enduring relevance across the lifespan, but may miss or fail to replicate effects that exist or are more dominant only in late or early life. Naturally, there is a greater preponderance of apoptotic events in an elderly sample and more developmental or synaptogenic processes in the younger samples. For this reason, genome-wide meta-analyses must not regard failure to replicate as a sign that gene is not influential in a given part of the lifespan, or in a given cohort or continent.

In a study of normal brain aging, Seshadri and colleagues (2007) investigated genetic associations with measures of total cerebral brain volume, lobar, ventricular and white matter hyperintensity volumes, and scores on six cognitive tests. They identified three SNPs (located in ERBB4, PDLIM5, and RFX4) that were associated both with measures of frontal or parietal brain volumes and with tests of executive function and abstract reasoning. These results did not survive testing for multiple comparisons, but they may be used to generate future hypotheses or to offer support to findings in future GWA studies [124]. As this study was one of brain aging rather than of $\mathrm{AD}$, cognitively normal adults were studied and not all measures examined were specific to AD risk. Therefore, some of the SNPs generated may relate more to brain aging or normal development than to $\mathrm{AD}$ risk.

Two GWA studies that we know of have examined endophenotypes in healthy young adults-a GWA study of caudate volume in 1198 young and old adults [123] and the first voxelwise GWA study of diffusion tensor images [125]. Further studies that focus on brain measurements specific to AD would be useful additions to the field. Since the brain differences that are likely to occur in normal adults are subtle compared to those in studies of a brain disease, very large numbers of subjects are needed to perform GWA in healthy young adults and to show that the results are reliable and reproducible across independent samples. The ENIGMA network brings together researchers in imaging and genetics, and current analyses are probing structural and functional neuroimaging and GWA data from over 10,000 subjects. This type of effort will prove invaluable in replication studies. ENIGMA also allows for the identification of "slow climbers"-genetic variants that may not be significant in all studies or in any one study alone, but may become highly significant when data is aggregated across studies.

GWA and vGWA involve huge numbers of comparisons, which may result in false positives if not properly controlled. It is therefore incumbent upon readers of such studies to critically evaluate the significance levels of the studies before basing potentially costly experiments upon their results. However, such exploratory studies may provide information that would not otherwise be easily obtained and can be extremely useful in focusing future work. For instance, one might not collect thousands of MRI scans to test the effect of one SNP previously found to be marginally significant. However, it may make sense to test the effects of that SNP in conjunction with other more established ones when GWA data has already been collected and the MRI scans have been physically analyzed. In this way, it is possible to build easily on previous results until they are strong enough to warrant independent exploration. 
In addition, the large number of statistical tests involved in a genome-wide and/or image wide search requires special methods to boost power, including gene-based tests [126], ridge regression models [127], multilocus modeling, and meta-analysis. In the first voxelwise GWA studies of MRI and DTI $[113,125]$, no single SNP passed the conventional threshold for genome-wide significance; even so, the top SNPs can be prioritized when screening new imaging datasets for replications of these hits. Efforts such as the ENIGMA consortium have found that some SNPs identified by GWA are robustly associated with hippocampal volume and total brain volume. Although no single contributing site was able to find results that were genome-wide significant, the effects of several SNPs were robustly replicated when meta-analyzed across imaging datasets of more than 6400 subjects from 16 imaging sites [128].

\section{Multiple Genetic Risk Factors}

A statistical test of association between a set of SNPs and a disease can offer far greater power and success in determining genetic risk than tests of single SNPs [129]. This is in part because the risk conferred by different SNPs may depend on the context and on several demographic and environmental factors - the age of the cohort, their educational level, and even their socioeconomic status [130]. Because of this, more complex models of gene action in $\mathrm{AD}$ are likely to include not only multiple SNPs, but also environmental and other risk factors that affect whether those variants are relevant or innocuous.

Multilocus genetic modeling refers to a large class of methods that assesses the effects of sets of SNPs-within the same or different genes-in predicting clinical diagnosis, prognosis, or disease risk. Looking at the additive or epistatic (interactive) effects of multiple risk gene variants may be useful, especially when the genes in question have similar effects. For instance, Szolnoki and colleagues (2003) found in 961 subjects that carriers of APOE2 or APOE4 had increased risk of white matter hyperintensities in their brains only if they also carried risk variants in the $A C E$ or MTHFR (methylenetetrahydrofolate reductase (NAD $(\mathrm{P}) \mathrm{H})$ ) genes [131]. All three are listed as top AD risk genes [9] and also affect the cardiovascular system, so it makes sense to examine their additive effects on the brain. Multilocus genetic models can assess the combined effects of multiple gene sets acting together.

Because adjacent SNPs in a genome-wide association study may be highly correlated due to linkage disequilibrium, it is not possible to use standard statistical methods, such as multiple regression, to identify which SNPs exert an influence on a trait. Machine learning methods that can cope with high-dimensional sets of predictors include such techniques as penalized regression, adaptive boosting, and the "Bayesian lasso". All of these methods have been used widely in quantitative genetics, and show substantial promise for analyzing brain imaging phenotypes.

Multilocus models are conceptually attractive as they allow the testing of the aggregate effect of several SNPs in the same gene, which individually may have effects too weak to detect on their own. In one study [126], we applied a novel method, multivariate principal components regression (PCReg) to test whole genes for associations with imaging data, not just single SNPs within them. When multiple partial- $F$ tests were used to test the joint effect of all SNPs in a gene on regional brain volume differences, we identified several genes associated with brain-related disorders that are highly relevant to brain structure. GRB-associated binding protein 2 gene, GAB2 - the most significantly associated gene in our analysis - has previously been linked to late-onset $\mathrm{AD}$, and $G A B 2$ associations showed a symmetric signal in the white matter superior to the lateral ventricles. As a caveat, other methods that include multiple SNPs can sacrifice power as increasingly stringent corrections are applied to guard against finding spurious associations using highdimensional regression models with many parameters. Even so, efficient gene-based association tests across the whole brain can drastically reduce the number of independent tests performed, detecting known genes highly relevant to brain structure that may be missed by univariate methods alone.

\section{Conclusion}

In summary, using neuroimaging endophenotypes to identify $\mathrm{AD}$ risk factors is a new and promising enterprise. Future studies of the combined effects of multiple candidate risk factors, and an expansion of genome-wide studies to a wide variety of imaging modalities may help generate new endophenotypes that predict AD. Additionally, a focus on particular contributions to $\mathrm{AD}$ risk, such as deposition of AD-related pathology, or developmental vulnerabilities might prove productive in unraveling disease complexity. For instance, searching for gene variants of an $\mathrm{AD}$ endophenotype in a large sample of healthy young adults would be most likely to uncover genes affecting developmental vulnerabilities to the disease. In contrast, examining a given endophenotype in AD and MCI patients while controlling for gene variants known to affect that measure in younger adults would boost the power to identify polymorphisms related to $\mathrm{AD}$ processes and cumulative environmental risk factors, while excluding some developmental effects. Careful selection of endophenotype, data pooling across studies and analysis of multiple different aspects of $\mathrm{AD}$ pathology and vulnerabilities may prove invaluable in the quest to explain the genetic risk for $\mathrm{AD}$.

\section{References}

[1] A. L. M. Bergem, K. Engedal, and E. Kringlen, "The role of heredity in late-onset Alzheimer disease and vascular dementia: a twin study," Archives of General Psychiatry, vol. 54, no. 3, pp. 264-270, 1997.

[2] M. Gatz, N. L. Pedersen, S. Berg et al., "Heritability for Alzheimer's disease: the study of dementia in Swedish twins," Journals of Gerontology. Series A, vol. 52, no. 2, pp. M117M125, 1997.

[3] M. Gatz, C. A. Reynolds, L. Fratiglioni et al., "Role of genes and environments for explaining Alzheimer disease," Archives of General Psychiatry, vol. 63, no. 2, pp. 168-174, 2006. 
[4] A. Goate, M. C. Chartier-Harlin, M. Mullan et al., "Segregation of a missense mutation in the amyloid precursor protein gene with familial Alzheimer's disease," Nature, vol. 349, no. 6311, pp. 704-706, 1991.

[5] R. Sherrington, E. I. Rogaev, Y. Liang et al., "Cloning of a gene bearing missense mutations in early-onset familial Alzheimer's disease," Nature, vol. 375, no. 6534, pp. 754-760, 1995.

[6] E. Levy-Lahad, W. Wasco, P. Poorkaj et al., "Candidate gene for the chromosome 1 familial Alzheimer's disease locus," Science, vol. 269, no. 5226, pp. 973-977, 1995.

[7] E. I. Rogaev, R. Sherrington, E. A. Rogaeva et al., "Familial Alzheimer's disease in kindreds with missense mutations in a gene on chromosome 1 related to the Alzheimer's disease type 3 gene," Nature, vol. 376, no. 6543, pp. 775-778, 1995.

[8] E. H. Corder, A. M. Saunders, W. J. Strittmatter et al., "Gene dose of apolipoprotein E type 4 allele and the risk of Alzheimer's disease in late onset families," Science, vol. 261, no. 5123, pp. 921-923, 1993.

[9] L. Bertram, M. B. McQueen, K. Mullin, D. Blacker, and R. E. Tanzi, "Systematic meta-analyses of Alzheimer disease genetic association studies: the AlzGene database," Nature Genetics, vol. 39, no. 1, pp. 17-23, 2007.

[10] N. Ertekin-Taner, "Genetics of Alzheimer disease in the preand post-GWAS era," Alzheimer's Research and Therapy, vol. 2, no. 1, page 3, 2010.

[11] D. Harold, R. Abraham, P. Hollingworth et al., "Genomewide association study identifies variants at CLU and PICALM associated with Alzheimer's disease," Nature Genetics, vol. 41, no. 10, pp. 1088-1093, 2009.

[12] S. Seshadri, A. L. Fitzpatrick, M. A. Ikram et al., "Genomewide analysis of genetic loci associated with Alzheimer disease," Journal of the American Medical Association, vol. 303, no. 18, pp. 1832-1840, 2010.

[13] J.-C. Lambert, S. Heath, G. Even et al., "Genome-wide association study identifies variants at CLU and CR1 associated with Alzheimer's disease," Nature Genetics, vol. 41, no. 10, pp. 1094-1099, 2009.

[14] T. Zetzsche, D. Rujescu, J. Hardy, and H. Hampel, "Advances and perspectives from genetic research: development of biological markers in Alzheimer's disease," Expert Review of Molecular Diagnostics, vol. 10, pp. 667-690, 2010.

[15] G. W. Small, L. M. Ercoli, D. H. S. Silverman et al., "Cerebral metabolic and cognitive decline in persons at genetic risk for Alzheimer's disease," Proceedings of the National Academy of Sciences of the United States of America, vol. 97, no. 11, pp. 6037-6042, 2000.

[16] L. Mosconi, S. De Santi, M. Brys et al., "Hypometabolism and altered cerebrospinal fluid markers in normal apolipoprotein E E4 carriers with subjective memory complaints," Biological Psychiatry, vol. 63, no. 6, pp. 609-618, 2008.

[17] E. M. Reiman, K. Chen, G. E. Alexander et al., "Correlations between apolipoprotein E $\varepsilon 4$ gene dose and brain-imaging measurements of regional hypometabolism," Proceedings of the National Academy of Sciences of the United States of America, vol. 102, no. 23, pp. 8299-8302, 2005.

[18] S. Y. Bookheimer, M. H. Strojwas, M. S. Cohen et al., "Patterns of brain activation in people at risk for Alzheimer's disease," New England Journal of Medicine, vol. 343, no. 7, pp. 450-456, 2000.

[19] N. A. Suthana, A. Krupa, M. Donix et al., "Reduced hippocampal CA2, CA3, and dentate gyrus activity in asymptomatic people at genetic risk for Alzheimer's disease," NeuroImage, vol. 53, no. 3, pp. 1077-1084, 2009.
[20] M. W. Bondi, W. S. Houston, L. T. Eyler, and G. G. Brown, "fMRI evidence of compensatory mechanisms in older adults at genetic risk for Alzheimer disease," Neurology, vol. 64, no. 3, pp. 501-508, 2005.

[21] S. D. Han, W. S. Houston, A. J. Jak et al., "Verbal pairedassociate learning by APOE genotype in non-demented older adults: fMRI evidence of a right hemispheric compensatory response," Neurobiology of Aging, vol. 28, no. 2, pp. 238-247, 2007.

[22] N. Filippini, B. J. MacIntosh, M. G. Hough et al., "Distinct patterns of brain activity in young carriers of the APOE- $\varepsilon 4$ allele," Proceedings of the National Academy of Sciences of the United States of America, vol. 106, no. 17, pp. 7209-7214, 2009.

[23] M. Pihlajamaki, K. O’Keefe, L. Bertram et al., "Evidence of altered posteromedial cortical fMRI activity in subjects at risk for Alzheimer disease," Alzheimer Disease and Associated Disorders, vol. 24, no. 1, pp. 28-36, 2010.

[24] J. Lind, J. Persson, M. Ingvar et al., "Reduced functional brain activity response in cognitively intact apolipoprotein $\mathrm{E} \varepsilon 4$ carriers," Brain, vol. 129, no. 5, pp. 1240-1248, 2006.

[25] M. A. Trivedi, T. W. Schmitz, M. L. Ries et al., "Reduced hippocampal activation during episodic encoding in middleaged individuals at genetic risk of Alzheimer's disease: a cross-sectional study," BMC Medicine, vol. 4, article 1, 2006.

[26] G. Xu, D. G. Mclaren, M. L. Ries et al., "The influence of parental history of Alzheimer's disease and apolipoprotein $\mathrm{E}$ $\varepsilon 4$ on the BOLD signal during recognition memory," Brain, vol. 132, no. 2, pp. 383-391, 2009.

[27] A. C. Burggren, M. M. Zeineh, A. D. Ekstrom et al., "Reduced cortical thickness in hippocampal subregions among cognitively normal apolipoprotein E e4 carriers," NeuroImage, vol. 41, no. 4, pp. 1177-1183, 2008.

[28] F. Crivello, H. Lemaître, C. Dufouil et al., "Effects of ApoE$\varepsilon 4$ allele load and age on the rates of grey matter and hippocampal volumes loss in a longitudinal cohort of 1186 healthy elderly persons," NeuroImage, vol. 53, no. 3, pp. 10641069, 2010.

[29] P. Shaw, J. P. Lerch, J. C. Pruessner et al., "Cortical morphology in children and adolescents with different apolipoprotein E gene polymorphisms: an observational study," Lancet Neurology, vol. 6, no. 6, pp. 494-500, 2007.

[30] N. Schuff, N. Woerner, L. Boreta et al., "MRI of hippocampal volume loss in early Alzheimer's disease in relation to ApoE genotype and biomarkers," Brain, vol. 132, no. 4, pp. 10671077, 2009.

[31] A. J. Jak, W. S. Houston, B. J. Nagel, J. Corey-Bloom, and M. W. Bondi, "Differential cross-sectional and longitudinal impact of APOE genotype on hippocampal volumes in nondemented older adults," Dementia and Geriatric Cognitive Disorders, vol. 23, no. 6, pp. 382-389, 2007.

[32] J. Nierenberg, N. Pomara, M. J. Hoptman, J. J. Sidtis, B. A. Ardekani, and K. O. Lim, "Abnormal white matter integrity in healthy apolipoprotein E epsilon4 carriers," NeuroReport, vol. 16, no. 12, pp. 1369-1372, 2005.

[33] J. Persson, J. Lind, A. Larsson et al., "Altered brain white matter integrity in healthy carriers of the APOE $\varepsilon 4$ allele: a risk for AD?" Neurology, vol. 66, no. 7, pp. 1029-1033, 2006.

[34] C. D. Smith, H. Chebrolu, A. H. Andersen et al., "White matter diffusion alterations in normal women at risk of Alzheimer's disease," Neurobiology of Aging, vol. 31, no. 7, pp. 1122-1131, 2010. 
[35] C. Wang, G. T. Stebbins, D. A. Medina et al., "Atrophy and dysfunction of parahippocampalwhite matter in mild Alzheimer's disease," Neurobiology of Aging. In press.

[36] M. Thambisetty, L. Beason-Held, Y. An, M. A. Kraut, and S. M. Resnick, "APOE $\varepsilon 4$ genotype and longitudinal changes in cerebral blood flow in normal aging," Archives of Neurology, vol. 67, no. 1, pp. 93-98, 2010.

[37] A. S. Fleisher, K. M. Podraza, K. J. Bangen et al., "Cerebral perfusion and oxygenation differences in Alzheimer's disease risk," Neurobiology of Aging, vol. 30, no. 11, pp. 1737-1748, 2009.

[38] P. Hogh, G. M. Knudsen, K. H. Kjaer, O. S. Jørgensen, O. B. Paulson, and G. Waldemar, "Single photon emission computed tomography and apolipoprotein E in Alzheimer's disease: impact of the $\varepsilon 4$ allele on regional cerebral blood flow," Journal of Geriatric Psychiatry and Neurology, vol. 14, no. 1, pp. 42-51, 2001.

[39] N. Scarmeas, C. G. Habeck, J. Hilton et al., "APOE related alterations in cerebral activation even at college age," Journal of Neurology, Neurosurgery and Psychiatry, vol. 76, no. 10, pp. 1440-1444, 2005.

[40] G. W. Small, P. Siddarth, A. C. Burggren et al., "Influence of cognitive status, age, and APOE-4 genetic risk on brain FDDNP positron-emission tomography imaging in persons without dementia," Archives of General Psychiatry, vol. 66, no. 1, pp. 81-87, 2009.

[41] A. Drzezga, T. Grimmer, G. Henriksen et al., "Effect of APOE genotype on amyloid plaque load and gray matter volume in Alzheimer disease," Neurology, vol. 72, no. 17, pp. 1487-1494, 2009.

[42] C. C. Rowe, K. A. Ellis, M. Rimajova et al., "Amyloid imaging results from the Australian Imaging, Biomarkers and Lifestyle (AIBL) study of aging," Neurobiology of Aging, vol. 31, no. 8, pp. 1275-1283, 2010.

[43] E. M. Reiman, K. Chen, X. Liu et al., "Fibrillar amyloid- $\beta$ burden in cognitively normal people at 3 levels of genetic risk for Alzheimer's disease," Proceedings of the National Academy of Sciences of the United States of America, vol. 106, no. 16, pp. 6820-6825, 2009.

[44] J. C. Morris, C. M. Roe, C. Xiong et al., "APOE predicts amyloid-beta but not tau Alzheimer pathology in cognitively normal aging," Annals of Neurology, vol. 67, no. 1, pp. 122$131,2010$.

[45] N. Scarmeas and Y. Stern, "Imaging studies and APOE genotype in persons at risk for Alzheimer's disease," Current Psychiatry Reports, vol. 8, no. 1, pp. 11-17, 2006.

[46] S. Bookheimer and A. Burggren, "APOE-4 genotype and neurophysiological vulnerability to Alzheimer's and cognitive aging," Annual Review of Clinical Psychology, vol. 5, pp. 343-362, 2009.

[47] A. Biff, C. D. Anderson, R. S. Desikan et al., "Genetic variation and neuroimaging measures in Alzheimer disease," Archives of Neurology, vol. 67, no. 6, pp. 677-685, 2010.

[48] R. C. Petersen, "Mild cognitive impairment: transition between aging and Alzheimer's disease," Neurologia, vol. 15, no. 3, pp. 93-101, 2000.

[49] K. R. Bales, T. Verina, D. J. Cummins et al., "Apolipoprotein $\mathrm{E}$ is essential for amyloid deposition in the APP(V717F) transgenic mouse model of Alzheimer's disease," Proceedings of the National Academy of Sciences of the United States of America, vol. 96, no. 26, pp. 15233-15238, 1999.

[50] Y. Shimoda and K. Watanabe, "Contactins: emerging key roles in the development and function of the nervous system," Cell Adhesion and Migration, vol. 3, no. 1, pp. 6470, 2009.

[51] B. V. Zlokovic, C. L. Martel, J. B. Mackic et al., "Brain uptake of circulating apolipoproteins J and E complexed to Alzheimer's amyloid $\beta$," Biochemical and Biophysical Research Communications, vol. 205, no. 2, pp. 1431-1437, 1994.

[52] A. Harel, F. Wu, M. P. Mattson, C. M. Morris, and P. J. Yao, "Evidence for CALM in directing VAMP2 trafficking," Traffic, vol. 9, no. 3, pp. 417-429, 2008.

[53] M. H. Butler, C. David, G. C. Ochoa et al., "Amphiphysin II (SH3p9; BIN1), a member of the amphiphysin/Rvs family, is concentrated in the cortical cytomatrix of axon initial segments and nodes of ranvier in brain and around $\mathrm{T}$ tubules in skeletal muscle," Journal of Cell Biology, vol. 137, no. 6, pp. 1355-1367, 1997.

[54] M. N. Braskie, N. Jahanshad, J. L. Stein et al., "Common Alzheimer's disease risk variant within the CLU gene affects white matter microstructure in young adults," San Diego, Calif, USA, 2010.

[55] G. Dati, A. Quattrini, L. Bernasconi et al., "Beneficial effects of r-h-CLU on disease severity in different animal models of peripheral neuropathies," Journal of Neuroimmunology, vol. 190, no. 1-2, pp. 8-17, 2007.

[56] E. Rogaeva, Y. Meng, J. H. Lee et al., "The neuronal sortilin-related receptor SORL1 is genetically associated with Alzheimer disease," Nature Genetics, vol. 39, no. 2, pp. 168$177,2007$.

[57] K. Ohwaki, H. Bujo, M. Jiang, H. Yamazaki, W. J. Schneider, and Y. Saito, "A secreted soluble form of LR11, specifically expressed in intimal smooth muscle cells, accelerates formation of lipid-laden macrophages," Arteriosclerosis, Thrombosis, and Vascular Biology, vol. 27, no. 5, pp. 1050-1056, 2007.

[58] K. T. Cuenco, K. L. Lunetta, C. T. Baldwin et al., "Association of distinct variants in SORL1 with cerebrovascular and neurodegenerative changes related to Alzheimer disease," Archives of Neurology, vol. 65, no. 12, pp. 1640-1648, 2008.

[59] M. Schuur, J. C. Van Swieten, S. Schol-Gelok et al., "Genetic risk factors for cerebral small-vessel disease in hypertensive patients from a genetically isolated population," Journal of Neurology, Neurosurgery and Psychiatry, vol. 82, no. 1, pp. 4144, 2011.

[60] C. Babiloni, L. Benussi, G. Binetti et al., "Genotype (cystatin C) and EEG phenotype in Alzheimer disease and mild cognitive impairment: a multicentric study," NeuroImage, vol. 29, no. 3, pp. 948-964, 2006.

[61] H. V. Vinters, G. S. Nishimura, D. Lenard Secor, and W. M. Pardridge, "Immunoreactive A4 and gamma-trace peptide colocalization in amyloidotic arteriolar lesions in brains of patients with Alzheimer's disease," American Journal of Pathology, vol. 137, no. 2, pp. 233-240, 1990.

[62] P. Taupin, J. Ray, W. H. Fischer et al., "FGF-2-responsive neural stem cell proliferation requires $\mathrm{CCg}$, a novel autocrine/paracrine cofactor," Neuron, vol. 28, no. 2, pp. 385397, 2000.

[63] Z. Zhang, L. Deng, F. Bai et al., "Alteration of resting brain function by genetic variation in angiotensin converting enzyme in amnestic-type mild cognitive impairment of Chinese Han," Behavioural Brain Research, vol. 208, no. 2, pp. 619-625, 2010.

[64] O. Von Bohlen and Halbach, "Angiotensin IV in the central nervous system," Cell and Tissue Research, vol. 311, no. 1, pp. 1-9, 2003.

[65] N. Purandare, R. C. Oude Voshaar, Y. Davidson et al., "Deletion/insertion polymorphism of the angiotensin-converting 
enzyme gene and white matter hyperintensities in dementia: a pilot study," Journal of the American Geriatrics Society, vol. 54, no. 9, pp. 1395-1400, 2006.

[66] Z. Szolnoki, F. Somogyvari, A. Kondacs, M. Szabó, and L. Fodor, "Evaluation of the roles of common genetic mutations in leukoaraiosis," Acta Neurologica Scandinavica, vol. 104, no. 5, pp. 281-287, 2001.

[67] D. Bartres-Faz, C. Junque, I. C. Clemente et al., "MRI and genetic correlates of cognitive function in elders with memory impairment," Neurobiology of Aging, vol. 22, no. 3, pp. 449-459, 2001.

[68] K. Sleegers, T. den Heijer, E. J. van Dijk et al., "ACE gene is associated with Alzheimer's disease and atrophy of hippocampus and amygdala," Neurobiology of Aging, vol. 26, no. 8, pp. 1153-1159, 2005.

[69] L. A. Farrer, T. Sherbatich, S. A. Keryanov et al., "Association between angiotensin-converting enzyme and Alzheimer disease," Archives of Neurology, vol. 57, no. 2, pp. 210-214, 2000.

[70] B. Palumbo, D. Cadini, G. Nocentini, E. Filipponi, M. L. Fravolini, and U. Senin, "Angiotensin converting enzyme deletion allele in different kinds of dementia disorders," Neuroscience Letters, vol. 267, no. 2, pp. 97-100, 1999.

[71] D. Erten-Lyons, A. Jacobson, P. Kramer, A. Grupe, and J. Kaye, "The FAS gene, brain volume, and disease progression in Alzheimer's disease," Alzheimer's and Dementia, vol. 6, no. 2, pp. 118-124, 2010.

[72] J. H. Su, A. J. Anderson, D. H. Cribbs et al., "Fas and Fas Ligand are associated with neuritic degeneration in the AD brain and participate in $\beta$-amyloid-induced neuronal death," Neurobiology of Disease, vol. 12, no. 3, pp. 182-193, 2003.

[73] M. Kivipelto, E. L. Helkala, M. P. Laakso et al., "Apolipoprotein E $\varepsilon 4$ allele, elevated midlife total cholesterol level, and high midlife systolic blood pressure are independent risk factors for late-life Alzheimer disease," Annals of Internal Medicine, vol. 137, no. 3, pp. 149-155, 2002.

[74] L. J. Launer, G. W. Ross, H. Petrovitch et al., "Midlife blood pressure and dementia: the Honolulu-Asia aging study," Neurobiology of Aging, vol. 21, no. 1, pp. 49-55, 2000.

[75] L. A. Profenno, A. P. Porsteinsson, and S. V. Faraone, "Metaanalysis of Alzheimer's disease risk with obesity, diabetes, and related disorders," Biological Psychiatry, vol. 67, no. 6, pp. 505-512, 2010.

[76] A. J. Ho, J. L. Stein, X. Hua et al., "A commonly carried allele of the obesity-related FTO gene is associated with reduced brain volume in the healthy elderly," Proceedings of the National Academy of Sciences of the United States of America, vol. 107, no. 18, pp. 8404-8409, 2010.

[77] T. M. Frayling, N. J. Timpson, M. N. Weedon et al., "A common variant in the FTO gene is associated with body mass index and predisposes to childhood and adult obesity," Science, vol. 316, no. 5826, pp. 889-894, 2007.

[78] C. A. Raji, A. J. Ho, N. N. Parikshak et al., "Brain structure and obesity," Human Brain Mapping, vol. 31, no. 3, pp. 353$364,2010$.

[79] A. J. Ho, C. A. Raji, J. T. Becker et al., "Obesity is linked with lower brain volume in $700 \mathrm{AD}$ and MCI patients," Neurobiology of Aging, vol. 31, no. 8, pp. 1326-1339, 2010.

[80] A. J. Ho, C. A. Raji, J. T. Becker et al., "The effects of physical activity, education, and body mass index on the aging brain," Human Brain Mapping. In press.

[81] J. L. Stein, X. Hua, J. H. Morra et al., "Genome-wide analysis reveals novel genes influencing temporal lobe structure with relevance to neurodegeneration in Alzheimer's disease," NeuroImage, vol. 51, no. 2, pp. 542-554, 2010.
[82] H. Braak and E. Braak, "Frequency of stages of Alzheimerrelated lesions in different age categories," Neurobiology of Aging, vol. 18, no. 4, pp. 351-357, 1997.

[83] A. J. Saykin, L. Shen, T. M. Foroud et al., "Alzheimer's Disease Neuroimaging Initiative biomarkers as quantitative phenotypes: genetics core aims, progress, and plans," Alzheimer's and Dementia, vol. 6, no. 3, pp. 265-273, 2010.

[84] I. I. Gottesman and T. D. Gould, "The endophenotype concept in psychiatry: etymology and strategic intentions," American Journal of Psychiatry, vol. 160, no. 4, pp. 636-645, 2003.

[85] P. Vemuri, H. J. Wiste, S. D. Weigand et al., "Serial MRI and CSF biomarkers in normal aging, MCI, and AD," Neurology, vol. 75, no. 2, pp. 143-151, 2010.

[86] Y. Y. Chou, N. Lepore, P. Saharan et al., "Ventricular maps in 804 ADNI subjects: correlations with CSF biomarkers and clinical decline," Neurobiology of Aging, vol. 31, no. 8, pp. 1386-1400, 2010.

[87] S. Kovacevic, M. S. Rafii, and J. B. Brewer, "High-throughput, fully automated volumetry for prediction of MMSE and CDR decline in mild cognitive impairment," Alzheimer Disease and Associated Disorders, vol. 23, no. 2, pp. 139-145, 2009.

[88] A. S. Fleisher, S. Sun, C. Taylor et al., "Volumetric MRI vs clinical predictors of Alzheimer disease in mild cognitive impairment," Neurology, vol. 70, no. 3, pp. 191-199, 2008.

[89] S. L. Risacher, A. J. Saykin, J. D. West, L. Shen, H. A. Firpi, and B. C. McDonald, "Baseline MRI predictors of conversion from MCI to probable AD in the ADNI cohort," Current Alzheimer Research, vol. 6, no. 4, pp. 347-361, 2009.

[90] S. Galluzzi, C. Geroldi, R. Ghidoni et al., "The new Alzheimer's criteria in a naturalistic series of patients with mild cognitive impairment," Journal of Neurology, vol. 257, no. 12, pp. 2004-2014, 2010.

[91] L. G. Apostolova, P. M. Thompson, A. E. Green et al., “3D comparison of low, intermediate, and advanced hippocampal atrophy in MCI," Human Brain Mapping, vol. 31, no. 5, pp. 786-797, 2010.

[92] X. Hua, A. D. Leow, N. Parikshak et al., "Tensor-based morphometry as a neuroimaging biomarker for Alzheimer's disease: an MRI study of $676 \mathrm{AD}, \mathrm{MCI}$, and normal subjects," NeuroImage, vol. 43, no. 3, pp. 458-469, 2008.

[93] W. S. Kremen, M. S. Panizzon, M. C. Neale et al., "Heritability of brain ventricle volume: converging evidence from inconsistent results," Neurobiology of Aging, 2010.

[94] A. L. DeStefano, S. Seshadri, A. Beiser et al., "Bivariate heritability of total and regional brain volumes: the Framingham study," Alzheimer Disease and Associated Disorders, vol. 23, no. 3, pp. 218-223, 2009.

[95] K. L. Lunetta, P. M. Erlich, K. T. Cuenco et al., "Heritability of magnetic resonance imaging (MRI) traits in Alzheimer disease cases and their siblings in the MIRAGE study," Alzheimer Disease and Associated Disorders, vol. 21, no. 2, pp. 85-91, 2007.

[96] J. C. Morris, C. M. Roe, E. A. Grant et al., "Pittsburgh compound $\mathrm{B}$ imaging and prediction of progression from cognitive normality to symptomatic Alzheimer disease," Archives of Neurology, vol. 66, no. 12, pp. 1469-1475, 2009.

[97] E. Scola, M. Bozzali, F. Agosta et al., "A diffusion tensor MRI study of patients with MCI and AD with a 2-year clinical follow-up," Journal of Neurology, Neurosurgery and Psychiatry, vol. 81, no. 7, pp. 798-805, 2010.

[98] M. C. Chiang, M. Barysheva, D. W. Shattuck et al., "Genetics of brain fiber architecture and intellectual performance," Journal of Neuroscience, vol. 29, no. 7, pp. 2212-2224, 2009. 
[99] A. L. Hinrichs, M. A. Mintun, D. Head et al., "Cortical binding of Pittsburgh compound B, an endophenotype for genetic studies of Alzheimer's disease," Biological Psychiatry, vol. 67, no. 6, pp. 581-583, 2010.

[100] S. M. Landau, D. Harvey, C. M. Madison et al., "Comparing predictors of conversion and decline in mild cognitive impairment," Neurology, vol. 75, no. 3, pp. 230-238, 2010.

[101] W. Jagust, A. Gitcho, F. Sun, B. Kuczynski, D. Mungas, and M. Haan, "Brain imaging evidence of preclinical Alzheimer's disease in normal aging," Annals of Neurology, vol. 59, no. 4, pp. 673-681, 2006.

[102] G. Chetelat, F. Eustache, F. Viader et al., "FDG-PET measurement is more accurate than neuropsychological assessments to predict global cognitive deterioration in patients with mild cognitive impairment," Neurocase, vol. 11, no. 1, pp. 14-25, 2005.

[103] L. L. Chao, S. T. Buckley, J. Kornak et al., "ASL perfusion MRI predicts cognitive decline and conversion from MCI to dementia," Alzheimer Disease and Associated Disorders, vol. 24, no. 1, pp. 19-27, 2010.

[104] L. Shen, S. Kim, S. L. Risacher et al., "Whole genome association study of brain-wide imaging phenotypes for identifying quantitative trait loci in MCI and AD: a study of the ADNI cohort," NeuroImage, vol. 53, no. 3, pp. 1051-1063, 2010.

[105] P. M. Thompson, K. M. Hayashi, G. De Zubicaray et al., "Dynamics of gray matter loss in Alzheimer's disease," Journal of Neuroscience, vol. 23, no. 3, pp. 994-1005, 2003.

[106] M. A. Carmona, K. K. Murai, L. Wang, A. J. Roberts, and E. B. Pasqualea, "Glial ephrin-A3 regulates hippocampal dendritic spine morphology and glutamate transport," Proceedings of the National Academy of Sciences of the United States of America, vol. 106, no. 30, pp. 12524-12529, 2009.

[107] M. Missler, R. E. Hammer, and T. C. Sudhof, "Neurexophilin binding to $\alpha$-neurexins. A single LNS domain functions as an independently folding ligand-binding unit," Journal of Biological Chemistry, vol. 273, no. 52, pp. 34716-34723, 1998.

[108] S. G. Potkin, G. Guffanti, A. Lakatos et al., "Hippocampal atrophy as a quantitative trait in a genome-wide association study identifying novel susceptibility genes for Alzheimer's Disease," PLoS ONE, vol. 4, no. 8, Article ID e6501, 2009.

[109] A. Martinez and E. Soriano, "Functions of ephrin/Eph interactions in the development of the nervous systemml: emphasis on the hippocampal system," Brain Research Reviews, vol. 49, no. 2, pp. 211-226, 2005.

[110] P. Kurup, Y. Zhang, J. Xu et al., “A $\beta$-mediated NMDA receptor endocytosis in Alzheimer's disease involves ubiquitination of the tyrosine phosphatase STEP $_{61}$, Journal of Neuroscience, vol. 30, no. 17, pp. 5948-5957, 2010.

[111] C. Balducci, R. Tonini, E. Zianni et al., "Cognitive deficits associated with alteration of synaptic metaplasticity precede plaque deposition in A $\beta$ PP23 transgenic mice," Journal of Alzheimer's Disease, vol. 21, no. 4, pp. 1367-1381, 2010.

[112] P. Xia, H.-S. V. Chen, D. Zhang, and S. A. Lipton, "Memantine preferentially blocks extrasynaptic over synaptic NMDA receptor currents in hippocampal autapses," Journal of Neuroscience, vol. 30, no. 33, pp. 11246-11250, 2010.

[113] J. L. Stein, X. Hua, S. Lee et al., "Voxelwise genome-wide association study (vGWAS)," NeuroImage, vol. 53, no. 3, pp. 1160-1174, 2010.

[114] W. L. Lau and S. B. Scholnick, "Identification of two new members of the CSMD gene family small star, filled," Genomics, vol. 82, pp. 412-415, 2003.
[115] I. Brunk, C. Blex, D. Speidel, N. Brose, and G. AhnertHilger, "Ca2+-dependent activator proteins of secretion promote vesicular monoamine uptake," Journal of Biological Chemistry, vol. 284, no. 2, pp. 1050-1056, 2009.

[116] L. A. Beckett, D. J. Harvey, A. Gamst et al., "The Alzheimer's Disease Neuroimaging Initiative: annual change in biomarkers and clinical outcomes," Alzheimer's and Dementia, vol. 6, no. 3, pp. 257-264, 2010.

[117] X. Hua, S. Lee, I. Yanovsky et al., "Optimizing power to track brain degeneration in Alzheimer's disease and mild cognitive impairment with tensor-based morphometry: an ADNI study of 515 subjects," NeuroImage, vol. 48, no. 4, pp. 668-681, 2009.

[118] K. Chen, J. B. S. Langbaum, A. S. Fleisher et al., "Twelvemonth metabolic declines in probable Alzheimer's disease and amnestic mild cognitive impairment assessed using an empirically pre-defined statistical region-of-interest: findings from the Alzheimer's Disease Neuroimaging Initiative," NeuroImage, vol. 51, no. 2, pp. 654-664, 2010.

[119] M.-C. Chiang, M. Barysheva, A. W. Toga et al., "BDNF gene effects on brain circuitry replicated in 455 twins," NeuroImage, vol. 55, no. 2, pp. 448-454, 2011.

[120] X. Wu, K. Chen, L. Yao et al., "Assessing the reliability to detect cerebral hypometabolism in probable Alzheimer's disease and amnestic mild cognitive impairment," Journal of Neuroscience Methods, vol. 192, no. 2, pp. 277-285, 2010.

[121] F. Dudbridge and A. Gusnanto, "Estimation of significance thresholds for genomewide association scans," Genetic Epidemiology, vol. 32, no. 3, pp. 227-234, 2008.

[122] P. M. Thompson, N. G. Martin, and M. J. Wright, "Imaging genomics," Current Opinion in Neurology, vol. 23, no. 4, pp. 368-373, 2010.

[123] J. L. Stein, D. P. Hibar, S. K. Madsen et al., "Discovery and replication of dopamine-related gene effects on caudate volume in young and elderly populations $(\mathrm{N}=1198)$ using genome-wide search," In press.

[124] S. Seshadri, A. L. de Stefano, R. Au et al., "Genetic correlates of brain aging on MRI and cognitive test measures: a genome-wide association and linkage analysis in the Framingham study," BMC Medical Genetics, vol. 8, article S15, supplement 1, 2007.

[125] D. P. Hibar, J. L. Stein, N. Jahanshad et al., "Voxelwise genome-wide association of Diffusion Tensor Images identifies putative novel variants influencing white matter integrity in 467 related young adults," San Diego, Calif, USA, 2010.

[126] D. P. Hibar, J. L. Stein, O. Kohannim et al., "Voxelwise gene-wide association study (vGeneWAS): multivariate gene-based association testing in 731 elderly subjects," Technical report, UCLA, http://www.loni.ucla.edu/ thompson/vGeneWAS/, 2010.

[127] O. Kohannim, X. Hua, and D. P. Hibar, "Boosting power for clinical trials using classifiers based on multiple biomarkers," Neurobiology of Aging, vol. 31, pp. 1429-1442, 2010.

[128] The ENIGMA Consortium, Genome-wide association metaanalyses of hippocampal volume: results from the ENIGMA Consortium, Quebec City, 2011.

[129] N. R. Wray and P. M. Visscher, "Narrowing the boundaries of the genetic architecture of schizophrenia," Schizophrenia Bulletin, vol. 36, no. 1, pp. 14-23, 2010.

[130] M. C. Chiang, K. L. McMahon, G. I. de Zubicaray et al., "Environmental factors surpass genetic influences in determining fiber microstructure as the brain develops: a diffusion tensor imaging study of 705 twins," San Diego, Calif, USA, 2010. 
[131] Z. Szolnoki, F. Somogyvari, A. Kondacs et al., "Specific APO E genotypes in combination with the ACE D/D or MTHFR 677TT mutation yield an independent genetic risk of leukoaraiosis," Acta Neurologica Scandinavica, vol. 109, no. 3, pp. 222-227, 2004.

[132] J. P. A. Ioannidis, P. Boffetta, J. Little et al., "Assessment of cumulative evidence on genetic associations: interim guidelines," International Journal of Epidemiology, vol. 37, no. 1, pp. 120-132, 2008.

[133] W. James Kent, C. W. Sugnet, T. S. Furey et al., "The human genome browser at UCSC," Genome Research, vol. 12, no. 6, pp. 996-1006, 2002. 


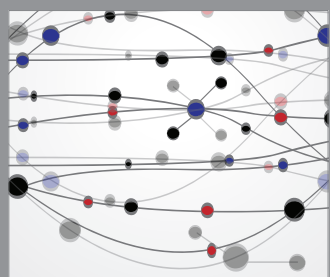

The Scientific World Journal
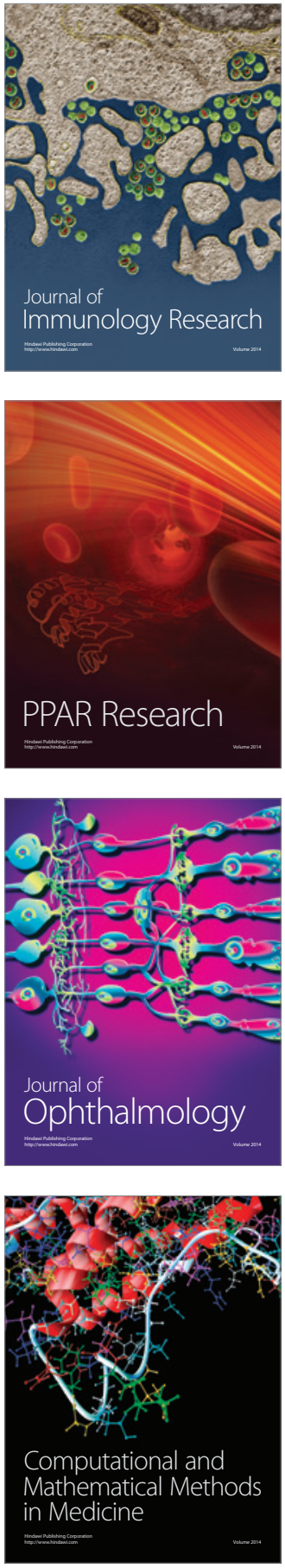

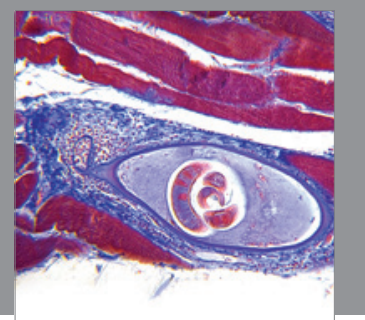

Gastroenterology

Research and Practice
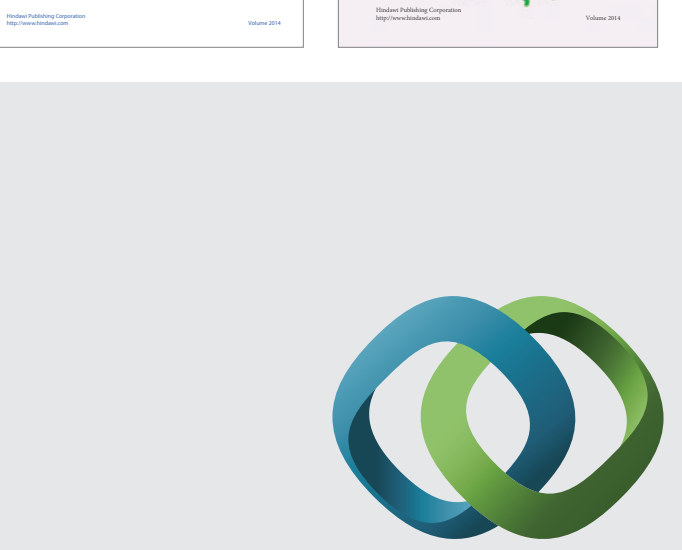

\section{Hindawi}

Submit your manuscripts at

http://www.hindawi.com
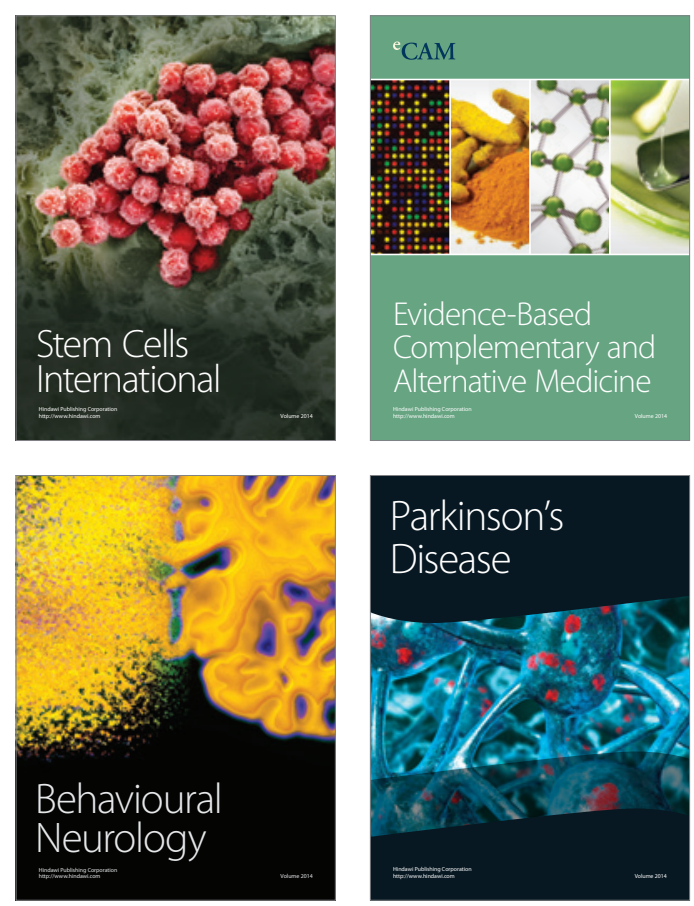

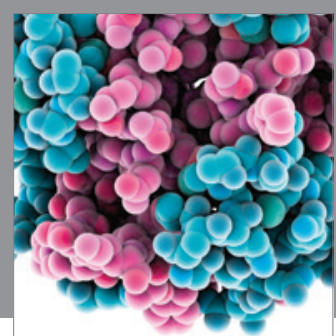

Journal of
Diabetes Research

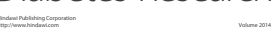

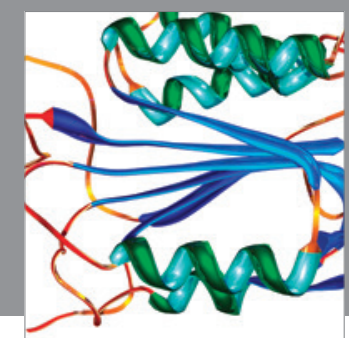

Disease Markers
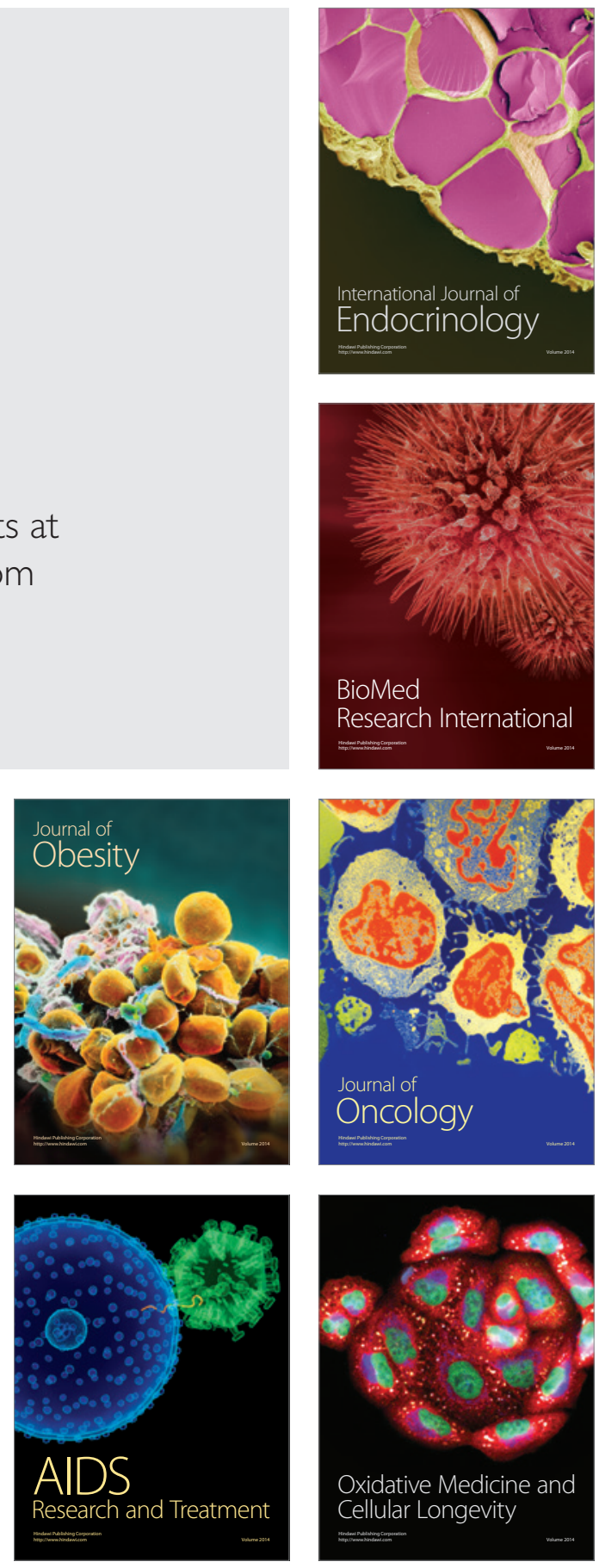